\title{
Aplicação dos mapas estratégicos do balanced scorecard na avaliação do Programa de Aquisição de Alimentos (PAA) em Martins/RN
}

Submissão: 21/05/2021

Aceite: $10 / 07 / 2021$

José Marcione da Costa ${ }^{1}$

Tales Wanderley Vital ${ }^{2}$

\begin{abstract}
Resumo
Este estudo tem por objetivo avaliar o Programa de Aquisição de Alimentos (PAA) no município de Martins/RN a partir da utilização dos Mapas Estratégicos do Balanced Scorecard. Trata-se de um estudo de caso qualitativo e quantitativo quanto ao seu método e descritivo quanto aos fins. No que se refere ao modelo analítico, foi utilizada a ferramenta dos Mapas Estratégicos do Balanced Scorecard adaptado ao setor público, baseado nas perspectivas do aprendizado e crescimento, eficiência, eficácia e efetividade. A coleta dos dados foi realizada por meio de pesquisa documental, realização de entrevistas e aplicação de formulários com sujeitos envolvidos na execução do programa no município. Os resultados mostraram que apesar da existência de algumas deficiências nas perspectivas relativas aos vetores de desempenho, principalmente no que se refere ao estabelecimento de parcerias, pode-se considerar que a maioria das medidas de resultado verificadas apresentaram avaliações positivas, tendo-se como exceções os serviços de prestação de assistência técnica na perspectiva da eficácia e os impactos sobre a produção e trabalho da família na propriedade na perspectiva da efetividade.
\end{abstract}

Palavras-chave: Mapas Estratégicos. Balanced Scorecard. Políticas Públicas. Programas Públicos. PAA.

\section{Application of strategic maps from balanced scorecard in the evaluation of the Food Purchase Program (PAA) in Martins-RN}

\begin{abstract}
This study aims to evaluate the Food Purchase Program (PAA) in the municipality of Martins/RN by using Strategic Maps of the Balanced Scorecard. This is a qualitative and quantitative case study as to its method and descriptive as to its ends. Regarding the analytical model, the Balanced Scorecard Strategic Maps tool adapted to the public sector was used, based on the perspectives of learning and growth, efficiency, efficacy and effectiveness. The data collection was carried out by means of documentary research, interviews and the application of forms with subjects involved in the execution of the program in the municipality. The results show that despite the existence of some deficiencies in the perspectives related to the performance vectors, especially regarding the establishment of partnerships, it can be considered that the majority of the verified result measures present positive evaluations. The exceptions manifests on the provision of technical assistance services in the perspective of efficiency and in the impacts on production and family's work on the property, from the perspective of effectiveness.
\end{abstract}

Keywords: Strategic Maps. Balanced scorecard. Public policy. PAA.

\section{Introdução}

No Brasil, a agricultura familiar sempre exerceu um notável papel econômico e social, fazendo parte das atividades produtivas do país desde o processo de ocupação do território nacional (PEREIRA e LOURENZANI, 2014; MATTEI, 2014). Segundo Lamarche (1993) a agricultura ${ }^{1}$ Doutorando em Agronegócios (UFRGS). Professor da Faculdade Evolução do Alto Oeste Potiguar (FACEP). https://orcid.org/0000-0003-0847-4414 E-mail: jose.marcione@hotmail.com

2 Pós-Doutorado em Desenvolvimento Territorial (Université Pierre Mendès France-Grenoble II). Doutorado em Economia (UFPE). Professor do Programa de Pós-Graduação em Administração Rural e Comunicação Rural da Universidade Federal Rural de Pernambuco (UFRPE). https://orcid.org/0000-0002-9925-3774

E-mail: talesvital@hotmail.com 
familiar pode ser compreendida como uma unidade de produção agrícola na qual o trabalho e a propriedade estão intimamente vinculados à família. Já a Lei no 11.326 de 24 de julho de 2006 estabelece alguns critérios para a definição de agricultor familiar, sendo eles: não deter uma propriedade com área maior do que 4 módulos fiscais, utilizar predominantemente mão-de-obra da própria família nas atividades econômicas do seu estabelecimento, possuir um percentual mínimo da renda familiar originada de atividades econômicas do seu estabelecimento e dirigir o estabelecimento ou empreendimento com sua família (BRASIL, 2006).

Em meados da década de 1990, com o objetivo de implantar uma cultura gerencial nas organizações orientada para a sociedade e para a obtenção de resultados, ocorreram transformações na administração pública brasileira que levaram a adoção do modelo gerencial de administração pública (BRESSER PEREIRA, 2005). Esse movimento de reestruturação do modelo gerencial brasileiro resultou em fortes pressões quanto à necessidade de prestação de contas das ações do Estado.

No que se refere as políticas públicas, essa reforma culminou com uma mudança no foco das avaliações que passou da verificação da conformidade legal para avaliação de seu desempenho (JANNUZZI, 2005). Para avaliar o desempenho das políticas públicas existe uma diversidade de indicadores de resultados. No entanto, aqueles relacionados aos critérios de eficiência, eficácia e efetividade podem ser considerados como os três principais (ANTICO e JANNUZZI, [2006?]; SANO e MONTENEGRO, 2013).

Reunindo argumento de Costa e Castanhar (2003), Ghelman (2006) e Silva Neto et al (2006), pode-se definir a eficiência como o acompanhamento de recursos e processos internos, a eficácia como o atingimento de metas físicas e qualidade na prestação de serviços referentes aos programas e a efetividade se relaciona com os efeitos esperados pela política sobre um determinado público. Assim, no processo de avaliação de políticas públicas torna-se necessária a determinação harmônica e sistemática de um conjunto de medidas de desempenho que possam englobar esses três critérios. Para tanto, existem diversos métodos de avaliação de desempenho que podem ser aplicados nesse sentido, dentre eles o balanced scorecard - BSC e seus mapas estratégicos (SANO e MONTENEGRO, 2013). Esta ferramenta foi desenvolvida inicialmente para ser aplicada a grandes empresas do setor privado, porém, adaptado ao setor público tendo como objetivo a avaliação de programas, permite gerenciar o alinhamento dos resultados das políticas públicas com suas respectivas missões (SILVA NETO et al, 2006).

Quanto as políticas públicas destinadas a classe dos agricultores familiares, destaca-se o Programa Nacional de Fortalecimento da Agricultura Familiar (PRONAF) que foi criado em 1996 e 
é tido como um marco de legitimação e de reconhecimento por parte do Estado desta categoria social (SCHNEIDER, MATTEI e CAZELLA, 2004). Posteriormente, para continuar atendendo as demandas desta classe, o Governo adotou um amplo conjunto de políticas direcionadas a essa categoria como o Programa Nacional de Crédito Fundiário (PNCF), o Programa de Garantia de Preços para a Agricultura Familiar (PGPAF), o Programa Nacional de Alimentação Escolar (PNAE) e o Programa de Aquisição de Alimentos (PAA), objeto de estudo deste artigo.

O Programa de Aquisição de Alimentos (PAA) foi criado em 2003, no âmbito das ações do Programa Fome Zero, com o intuito de incentivar a agricultura familiar e de promover o acesso a alimentação de pessoas em situação de insegurança alimentar e nutricional (BRASIL, 2003). Desde 2010 o PAA na modalidade Compra com Doação Simultânea atua de forma contínua no município de Martins-RN, sendo executado localmente por meio da Associação Martinense dos Produtores de Frutas (AMARFRUTAS) com o intuito de atingir seus principais objetivos que são: fortalecer a agricultura familiar no contexto local e reduzir a situação de insegurança alimentar das famílias atendidas pela rede socioassistencial do município.

Assim, considerando a importância da agricultura familiar no contexto da localidade escolhida para o estudo, a necessidade de avaliações sistemáticas de políticas públicas e ainda a atuação do PAA no âmbito local, esta pesquisa buscou responder a seguinte questão: o Programa de Aquisição de Alimentos na modalidade Compra com Doação Simultânea tem sido executado de forma eficiente, eficaz e efetiva no município de Martins-RN?

Diante do exposto, o objetivo geral do trabalho é avaliar a eficiência, eficácia e efetividade do Programa de Aquisição de Alimentos (PAA) na modalidade Compra com Doação Simultânea no município de Martins/RN a partir da aplicação da ferramenta dos Mapas Estratégicos do Balanced Scorecard. Quanto aos objetivos específicos, tem-se: a) identificar ações de promoção do aprendizado e crescimento dos ativos intangíveis envolvidos na execução do PAA; b) analisar a eficiência dos processos de gestão referentes ao PAA; c) verificar a eficácia quanto ao alcance das metas e a satisfação dos clientes diretos do PAA com a qualidade dos serviços do programa; e d) verificar se o PAA está tendo efetividade no atendimento da sua função social

O artigo está estruturado em mais quatro seções, além desta introdução. A segunda seção trata da revisão teórica na qual são apresentadas as origens e definições do balanced scorecard e dos mapas estratégicos e a adaptação do BSC e dos mapas estratégicos à avaliação de políticas públicas. A terceira seção descreve o modelo analítico utilizado e a metodologia do estudo. $\mathrm{Na}$ seção quatro são apresentados e discutidos os resultados da pesquisa. E, por fim, na quinta seção são expostas as considerações finais.

COLÓQUIO - Revista do Desenvolvimento Regional - Faccat - Taquara/RS - v. 18, n. 4, out./dez. 2021 


\section{Referencial teórico}

2.1 Balanced Scorecard e Mapas Estratégicos: histórico, definições e perspectivas

No início da década de 90, Kaplan e Norton (1992) chegaram à conclusão de que fatores como a adoção de novas tecnologias, a necessidade de gestão do conhecimento, de melhoria contínua e de inovação por parte das organizações fizeram com que os tradicionais indicadores de desempenho que evidenciavam apenas aspectos financeiros e que foram amplamente utilizados na era industrial, se tornassem ultrapassados.

Com isso, após a realização de um projeto de pesquisa que teve duração de um ano e contou com a participação de 12 empresas, desenvolveram um sistema de mensuração que objetivava resolver este problema considerando também medidas relacionadas a satisfação dos clientes, melhoria dos processos internos e capacidade de aprendizado (KAPLAN e NORTON, 1992). Este estudo que foi publicado na Havard Business Review com o título de "The Balanced Scorecard - measures that drive performance" resultou na criação de um novo sistema de mensuração de desempenho, que ficou conhecido como balanced scorecard. Após alguns anos, foi constatado que o balanced scorecard estava sendo utilizado pelas empresas não apenas como um sistema de medição, mas também como um sistema de gerenciamento estratégico que permitia conectar a estratégia de longo prazo das empresas às ações de curto prazo (KAPLAN e NORTON, 1996).

Quanto a sua definição, o balanced scorecard pode ser considerado "uma ferramenta completa que traduz a visão e a estratégia da empresa num conjunto coerente de medidas de desempenho" (KAPLAN e NORTON, 1997, p. 24). Esse conjunto de medidas de desempenho são organizados em quatro perspectivas, sendo elas: a do aprendizado e crescimento, a dos processos internos, a dos clientes e a financeira.

Definindo cada uma das quatro perspectivas do BSC, inicia-se com a perspectiva do aprendizado e crescimento. Esta perspectiva advém da intensa competição existente no ambiente organizacional, fato que impõe as empresas a necessidade de aprender, melhorar e inovar continuamente tanto em seus produtos quanto em seus processos de forma a criar maior valor para os clientes e proporcionar eficiência operacional a própria organização (KAPLAN e NORTON, 1992). As pessoas, os sistemas e os procedimentos organizacionais são considerados as três fontes principais do aprendizado e crescimento organizacional, no entanto sempre existem grandes lacunas entre essas fontes e os objetivos financeiros, dos clientes e dos processos internos do BSC (KAPLAN e NORTON, 1997). Como uma alternativa para o fechamento dessas 
lacunas "as empresas terão de investir na reciclagem de funcionários, no aperfeiçoamento da tecnologia da informação e dos sistemas, e no alinhamento dos procedimentos e rotinas organizacionais" (KAPLAN e NORTON, 1997, p. 29).

Já a perspectiva dos processos internos está voltada ao desenvolvimento de atividades internas da empresa que estejam relacionadas a processos, decisões e ações que sejam capazes de satisfazer às necessidades e as demandas dos clientes com excelência. Ao mesmo tempo, as medidas de desempenho criadas para esta perspectiva devem levar em consideração as expectativas dos acionistas quanto ao retorno financeiro proporcionado pela empresa (KAPLAN e NORTON, 1992; KAPLAN e NORTON, 1997).

A perspectiva do cliente requer que os gestores estabeleçam indicadores de desempenho que sejam relacionados as necessidades de satisfação dos clientes e que reflitam sobre aspectos importantes para esse público (KAPLAN e NORTON, 1992). Na ótica de Kaplan e Norton (1997, p. 26), as principais medidas de resultado relacionadas a perspectiva do cliente são: "satisfação do cliente, a retenção de clientes, a aquisição de novos clientes, a lucratividade dos clientes e a participação em contas (clientes) nos segmentos-alvo".

Por fim, com relação a perspectiva financeira, de acordo com Kaplan e Norton (1992) as medidas de desempenho financeiro indicam se a estratégia, sua implementação e execução estão produzindo melhorias no desempenho financeiro das empresas. Os indicadores da perspectiva financeira estão relacionados principalmente a lucratividade que pode ser medida por indicadores como a receita operacional, o retorno sobre o capital empregado, o valor econômico agregado aumento das vendas e fluxo de caixa (KAPLAN e NORTON, 1997).

Além das medidas de desempenho presentes nas perspectivas do BSC, um outro item dessa ferramenta é o mapa estratégico. Esse componente do BSC proporciona uma visão geral da interligação existente entre os objetivos e indicadores das quatro perspectivas e a estratégia da organização. Segundo Kaplan e Norton (2004, p. 55): “O mapa estratégico descreve a lógica da estratégia, mostrando com clareza os objetivos dos processos internos críticos que criam valor e os ativos intangíveis necessários para respaldá-los. O Balanced Scorecard traduz os objetivos do mapa estratégico em indicadores e metas."

Nas organizações do setor privado, considera-se que o êxito da estratégia ocorre quando se alcançam os resultados financeiros por meio da satisfação dos clientes. Por sua vez, para que haja criação de valor para os clientes, os processos internos são essenciais. Por fim, os processos internos são sustentados a partir do desenvolvimento e aperfeiçoamento dos ativos intangíveis presentes na perspectiva do aprendizado e crescimento (KAPLAN e NORTON, 2004). Essa relação 
de causa e efeito representada pela interligação existente entre as quatro perspectivas do BSC é essencial para o esclarecimento da lógica da estratégia das organizações e os mapas estratégicos mostram como esses componentes se conectam (KAPLAN e NORTON, 2004).

2.2 Balanced Scorecard e mapas estratégicos adaptados à avaliação de políticas públicas

A aplicação do balanced scorecard ainda não é comumente encontrada na administração pública, e para os casos de sua aplicação nesse cenário, são necessárias algumas adaptações da ferramenta (SILVA NETO et al, 2006). Assim, propondo um modelo de mapa estratégico e de BSC para avaliação de programas do setor público, Silva Neto et al (2006) adaptaram o balanced scorecard e fizeram uso das seguintes perspectivas: aprendizado e crescimento, eficiência, eficácia e efetividade. Dentre as quatro perspectivas, apenas a do aprendizado e crescimento permaneceu a mesma. A seguir é apresentado um exemplo de mapa estratégico aplicado à avaliação de políticas públicas.

Figura 1 - Modelo simples de mapa estratégico aplicado à avaliação de políticas públicas

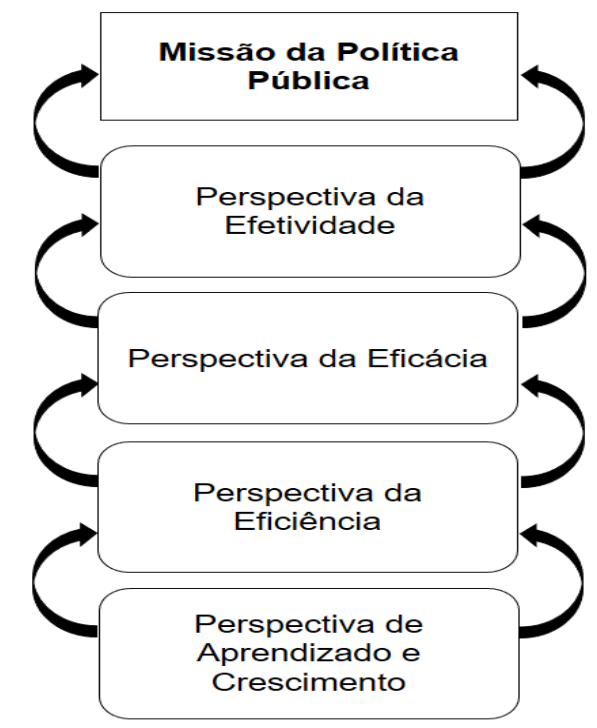

Fonte: elaborado com base em Kaplan e Norton (2004) e Silva Neto et al (2006)

Além das adaptações existentes nas perspectivas do mapa estratégico do BSC, quando se considera a sua aplicação para a avaliação de políticas públicas, a estratégia que está presente no topo do mapa do BSC do setor privado é substituída pela missão principal da política avaliada. Assim, torna-se possível desenhar um mapa estratégico para cada política, levando-se em 
consideração as suas especificidades e a função social que ela pretende atender (SILVA NETO et al, 2006).

Quanto as perspectivas do BSC adaptado a avaliação de políticas públicas, serão definidos os conceitos e as medidas de desempenho que podem ser aplicadas para a eficiência, a eficácia e a efetividade. A perspectiva do aprendizado e crescimento continua com o mesmo entendimento já descrito no modelo original.

Segundo Costa e Castanhar (2003) a eficiência está relacionada ao acompanhamento do uso de recursos e de processos internos. Tratada como perspectiva do BSC adaptado, a eficiência pode conter medidas de desempenho relacionadas à gestão orçamentária e financeira, gestão de relacionamentos e parcerias, gestão dos componentes e controle social do programa (SILVA NETO et al, 2006; MELO, 2013).

Já a eficácia, reunindo argumentos de Ghelman (2006) e Silva Neto et al (2006), refere-se ao atingimento de metas físicas e da prestação de serviços com qualidade. Com isso, as medidas de desempenho são elaboradas com o intuito de verificar o alcance das metas previamente estabelecidas e a percepção do público-alvo do programa em relação a qualidade dos serviços prestados pelos órgãos públicos responsáveis pelo programa avaliado.

Por último, define-se a efetividade. O conceito de efetividade está relacionado aos efeitos ou impacto social esperado pelo programa sobre uma população-alvo (COSTA e CASTANHAR, 2003; GHELMAN, 2006; SILVA NETO et al, 2006). Assim, a perspectiva da efetividade pode ser considerada como o objetivo máximo no mapa estratégico do BSC adaptado, sendo equivalente a perspectiva financeira do mapa estratégico do BSC original. Desta forma, deve-se desenvolver medidas de desempenho que estejam relacionadas aos objetivos do programa e os seus destinatários finais, para que estes emitam suas opiniões em relação aos efeitos dos programas.

\section{Modelo analítico e procedimentos metodológicos}

3.1 Modelo analítico: o mapa estratégico do BSC adaptado e aplicado à avaliação do PAA

Com o intuito de alcançar os objetivos estabelecidos neste estudo, foi adotado como modelo analítico o mapa estratégico do Balanced Scorecard. Assim, em relação as perspectivas de análise do modelo, optou-se pelas que mantêm maior proximidade com as práticas adotadas na gestão pública (SILVA NETO et al, 2006; MELO, 2013) em detrimento daquelas do modelo original, conforme apresentado na tabela 1.

COLÓQUIO - Revista do Desenvolvimento Regional - Faccat - Taquara/RS - v. 18, n. 4, out./dez. 2021 
Tabela 1 - Diferenças entre as perspectivas do BSC

\begin{tabular}{lr}
\hline Modelo Original & Modelo Adotado \\
\hline Finanças & Efetividade \\
\hline Clientes & Eficácia \\
\hline Processos internos & Eficiência \\
\hline Aprendizado e crescimento & Aprendizado e crescimento
\end{tabular}

Fonte: Elaborado pelos autores com base em Kaplan e Norton (1997), Silva Neto et el (2006) e Melo (2013)

No processo de construção do mapa estratégico foi considerada a orientação de Melo (2013) que diz que a sua formulação deve ser estruturada de cima para baixo, ou seja, parte-se da definição da missão do programa à perspectiva do aprendizado e crescimento. Seguindo essa orientação foi construído o mapa estratégico para a avaliação do PAA.

Figura 2 - Mapa estratégico aplicado na avaliação do PAA

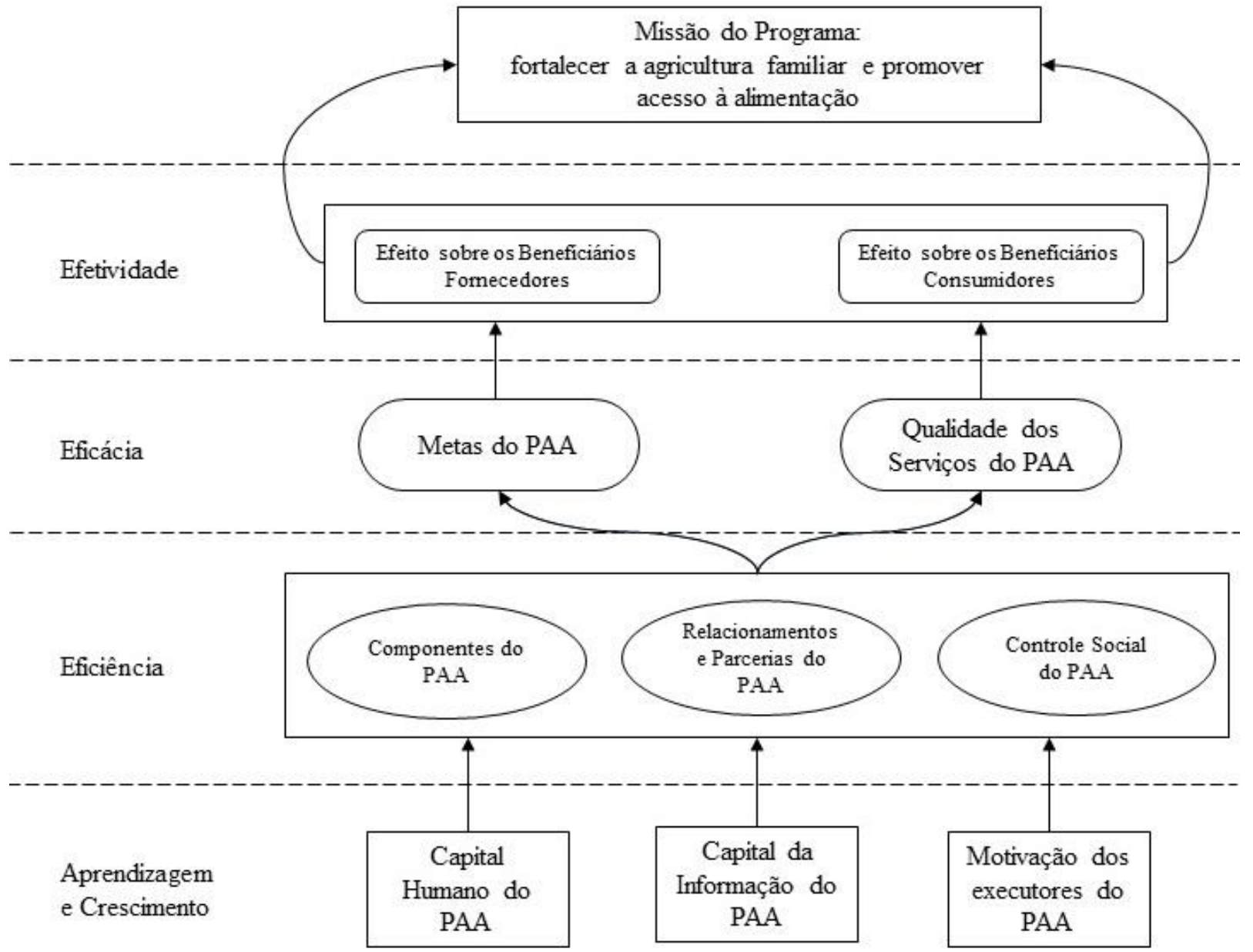

Fonte: elaborado pelos autores

Para isso, buscou-se compreender a lógica de funcionamento do programa, tendo como base o manual operativo (PAA) na modalidade compra com doação simultânea, que se trata da modalidade em operação no município de Martins-RN. Assim, foi possível adaptar os mapas estratégicos para avaliação de programas apresentados por Silva Neto et al (2006) e Melo (2013) 
para o caso específico do PAA. Na sequência, foi criado o mapa estratégico do BSC adaptado para avaliação do PAA, conforme apresentado na figura 2.

\subsection{Procedimentos metodológicos}

De acordo com Richardson et al (2015), a escolha do método deve ser orientada pela natureza do problema, pelo seu nível de aprofundamento e por sua capacidade de se apropriar aos objetivos do estudo. Assim, classificando esta pesquisa quanto ao método, utilizou-se das abordagens quantitativa e qualitativa. No que se refere aos objetivos, pode-se considerar este estudo como descritivo (VERGARA, 2014). E em relação aos procedimentos, considera-se esta pesquisa como um estudo de caso (YIN, 2015).

Quanto as fontes e procedimentos de coleta de dados, segundo orientação de Yin (2015), na condução de uma pesquisa caracterizada como estudo de caso é recomendada a busca por diferentes fontes de evidências para dar suporte e consistência aos resultados. Assim, foram utilizadas as seguintes técnicas para a coleta dos dados: pesquisa documental, na qual foram analisados documentos extraídos do site da CONAB contendo dados inerentes a quantidade de alimentos e recursos financeiros formalizados e executados no PAA no município investigado; realização de entrevistas estruturadas com o diretor geral e com o assistente técnico da associação responsável pela execução do programa a nível municipal com o intuito de levantar evidências alinhadas com as perspectivas do aprendizado e crescimento e da eficiência no modelo proposto, e aplicação de formulários com os beneficiários fornecedores e beneficiários consumidores. 0 quadro 1 , a seguir, apresenta o quantitativo de entrevistas realizadas e de formulários aplicados com os sujeitos da pesquisa. Ressalta-se ainda que os beneficiários fornecedores e consumidores foram codificados no texto com as abreviaturas B.F. e B.C. seguidos de um número na ordem que foram pesquisados.

Quadro 1 - Sujeitos participantes da pesquisa

\begin{tabular}{|l|r|c|}
\hline Instrumento de pesquisa & Sujeitos da pesquisa & Quantitativo de sujeitos \\
\hline Entrevista estruturada & Diretor Geral da associação & 1 \\
\hline Entrevista estruturada & Assistente Técnico da Associação & 1 \\
\hline Formulário & Beneficiários fornecedores & 20 \\
\hline Formulário & Beneficiários consumidores & 20 \\
\hline Total & & $\mathbf{4 2}$ \\
\hline
\end{tabular}

Fonte: Elaborado pelos autores

Quanto as estratégias de tratamento e análise dos dados, tem-se que os dados qualitativos das entrevistas foram transcritos e depois prosseguiram para a análise descritiva, e os dados 
quantitativos foram organizados em um banco de dados utilizando o software Microsoft Office Excel para cálculos de estatística descritiva e apresentados na forma de gráficos e tabelas.

\section{Resultados}

\subsection{Aprendizado e crescimento}

$\mathrm{Na}$ perspectiva do aprendizado e crescimento são analisados os ativos intangíveis necessários ao atingimento do objetivo geral do programa, sendo eles: o capital humano, o capital da informação e o capital organizacional, conforme visto a seguir.

\subsubsection{Capital humano}

O capital humano é o componente da perspectiva do aprendizado e crescimento que busca verificar o desenvolvimento de habilidades e conhecimentos que estejam alinhados com os resultados do programa, principalmente daqueles que ocupam funções estratégicas dentro da política (SILVA NETO et al, 2006). Assim, foi questionado ao diretor geral e ao assistente técnico da Associação sobre a existência de treinamento para os gestores do programa e sobre a periodicidade dessas capacitações. Ambos responderam de forma positiva o questionamento.

Eles sempre vêm, faz reunião e orienta como deve ser executado sabe. Eles têm esse treinamento. Em relação... sobre o PAA né. (Diretor Geral).

Sim, sim. Quem nos treinou foi o SENAI. A gente assinou um convênio via SEBRAE e veio um técnico do SENAI pra fazer um treinamento, montar né esse procedimento de conduta na entidade, na Associação em relação a polpa de frutas. (Assistente Técnico).

Diante dos comentários feitos pode-se destacar a atuação da CONAB responsável pela realização dos treinamentos referentes ao PAA, sendo realizados por meio de reuniões e visitas à Associação, conforme apontado na fala do Diretor Geral. Já o Assistente Técnico destaca que no período de abertura da Associação, houve treinamentos relacionados a técnicas de manuseio e transformação das frutas em polpas com o SENAI em parceria com o SEBRAE.

Quanto a periodicidade dos treinamentos, verifica-se que não há um período determinado para a realização. Eles aconteceram principalmente durante o processo de abertura da Associação e acontecem esporadicamente no cenário atual, conforme aponta a fala a seguir.

Quando a instituição ela é beneficiada com o projeto ela é chamada lá pra um treinamento, um dia de treinamento lá. Porque há algumas mudanças e é preciso a pessoa tá por dentro né de como fazer, de como acionar o PAA assim, de como fazer corretamente. E também eles mandam uma pessoa aqui pra vim visitar as instituições e os produtores e alguns até fazem reuniões e orientam também né. E outros visitam e nas visitas eles orientam a gente em alguma coisa que a gente esteja com dúvida ou também a instituição recebedora, os produtores também. (Diretor Geral). 
Destaca-se ainda na fala do Diretor Geral quando menciona que há capacitações quando são aprovados novos projetos e ocorrem mudanças dentro da estrutura do programa. A afirmação do diretor encontra amparo em Porto (2014, p. 116) quando diz que "O PAA está virando um emaranhado de normas, regras", fato que acarreta uma maior necessidade pela realização dos treinamentos visto que a cada ano ocorre uma série de alterações no programa que necessitam ser compreendidas por aqueles que o executam em nível local.

\subsubsection{Capital da informação}

Para Silva Neto et al (2006) o objetivo do capital da informação dentro do modelo consiste em disponibilizar sistemas de informação e aplicativos de gestão necessários para o atendimento da execução do programa. Assim, quando perguntados sobre a qualidade dos sistemas de informação utilizados no PAA, os dois entrevistados avaliaram as aplicações como muito boa e ainda julgaram que tais sistemas atendem plenamente todas as demandas necessárias para a operacionalização do programa, como é possível comprovar nas seguintes falas.

\footnotetext{
A gente entra no sistema e envia pra programa entrega né, PAANet Entrega, envia pra o sistema da CONAB e tem atendido. O pessoal elabora as notas e tem dado certo assim, nunca teve problema. (Diretor Geral).

Tudo isso tem explicado no MOC, aquele manual. E se precisar a gente liga pra eles e eles passam isso oral. A gente vai a Natal com uma certa constância aí Arruda que é comanda, todo o pessoal se houver alguma operação, qualquer coisa eles já conversam né. (Assistente Técnico).
}

Conforme explicado pelo diretor geral, a Associação nunca teve problemas nesse sentido, enquanto o assistente técnico ainda enfatizou a utilização do MOC (Manual de Operações da CONAB). O MOC se trata de um manual organizado pela CONAB que dispõe um conjunto de instrumentos, como instruções, normas e regulamentos, que são organizados por assuntos e que ficam disponíveis para os usuários desses sistemas.

Em relação as dificuldades de utilização desses sistemas, os entrevistados julgaram não haver nenhum tipo de complicação. Além disso, o assistente técnico da Associação apontou ainda que a sua participação nos procedimentos realizados no sistema já é praticamente nula, pois o diretor geral já se apropriou de conhecimentos necessários para realizá-los.

\subsubsection{Motivação}

Conforme Kaplan e Norton (1997), é relevante verificar a motivação dos funcionários, pois, mesmo que eles disponham de excelentes sistemas de informações e possuam as habilidades necessárias ao desenvolvimento de suas funções, não contribuirão para o alcance dos objetivos organizacionais se não estiverem motivados. Assim, foi perguntado aos gestores da execução do 
PAA/Compra com Doação Simultânea no município se eles se consideravam motivados em participar das ações do programa e quais fatores os motivavam. Na ocasião, os dois entrevistados responderam de forma positiva ao primeiro questionamento e justificaram as suas escolham com os comentários a seguir.

Trazer geração de renda né, principalmente pra os produtores, os beneficiários fornecedores que desperdiçavam suas frutas né. E também trazer alimentação pra o outro lado né, do lado dos consumidores. (Diretor Geral).

Eu acho que quando você tá desenvolvendo um programa que ele atende a sua comunidade é muito interessante certo. Dá um prazer enorme. Eu fiz algumas entrevistas com as diretoras das escolas no período e eram depoimentos muito agradáveis aos ouvidos da gente, você saber que tava participando de uma coisa que tava ajudando a sua comunidade, ajudando a sua cidade. (Assistente Técnico).

Conforme as falas identificam-se como fatores motivadores em participar do programa a sensação de estar contribuindo para o desenvolvimento do município quanto a geração de renda e fortalecimento da agricultura. Citou-se ainda a importância de participar de um programa que contribui para a redução da insegurança alimentar das pessoas carentes e a sensação de participação e cooperação social proporcionada a partir das ações desenvolvidas.

\subsection{Eficiência}

Neste tópico são analisados os resultados referentes a perspectiva da eficiência, que buscou analisar os seguintes aspectos: gestão dos componentes do programa, gestão de relacionamentos e parcerias e controle social do programa.

\subsubsection{Gestão dos componentes do programa}

Em relação ao detalhamento dos beneficiários fornecedores, foi constatado a adequação entre as falas dos respondentes e os requisitos básicos de elegibilidade estabelecidos na legislação do programa, que é ser agricultor familiar com DAP ativa.

Os beneficiários fornecedores são todos agricultores familiares. Agricultores e agricultoras. Porque aqui quarenta e poucos por cento são mulheres né. (Diretor Geral). Só agricultores familiares com DAP ativa. (Assistente Técnico).

Ressalta-se ainda que a gestão do programa também tem buscado atender aos parâmetros adicionais de execução do programa, já que tem um percentual maior que $40 \%$ de beneficiárias fornecedores mulheres. O relato exposto a seguir, apresenta como é feita a seleção dos beneficiários fornecedores e consumidores do programa no município.

Nos primeiros projetos a gente visitou, conversando sobre o projeto. Aí hoje devido o projeto já tá bem conhecido foi aumentando o número de produtores. Aqueles que 
foram beneficiados foram repassando... Mas a gente não deixa de fazer visitas, conversar, reuniões né. A gente faz a reunião aqui na Associação e esclarece sobre o projeto PAA sabe. Quais são suas vantagens, quais são suas finalidades, quais seus objetivos né e quais são também suas responsabilidades, tanto nossa aqui da Associação como as dos produtores. Então isso tem feito com que o projeto tenha um bom andamento né. $E$ os consumidores eles têm que prestar serviço social no caso né. No caso do CRAS que presta serviço social, as escolas elas têm seus alunos, ela presta serviço social né. (Diretor Geral).

Quanto aos beneficiários fornecedores, a partir da fala do diretor geral, verifica-se que inicialmente os gestores que fizeram o mapeamento dos beneficiários fornecedores e foram convidados a participar do programa. Outro fato que chamou atenção no comentário foi que após a estruturação do programa houve uma interação entre os produtores da cidade por meio da indicação de uns aos outros para participarem do programa.

Em relação aos beneficiários consumidores um fato especial chamou atenção. Foi relatado entre as entrevistas que inicialmente havia uma disputa política entre a prefeitura e a Associação, devido ao fato de o atual assistente técnico da instituição ter sido prefeito da cidade entre 2005 e 2008. Com isso, a prefeitura se recusou a cadastrar as escolas da rede municipal nos primeiros anos de atuação do programa, por existir uma aversão as atividades da Associação que, na visão da prefeita que geriu o município entre 2009 e 2012, tinha como objetivo angariar força política e votos em futuras eleições. Esse cenário fez com que nos anos iniciais de atuação do PAA/Doação Simultânea, a Associação distribuísse alimentos apenas para as escolas da rede estadual local e unidades recebedoras de cidades vizinhas.

\subsubsection{Gestão de relacionamentos e parcerias}

A gestão de relacionamentos e parcerias busca avaliar as relações da instituição executora do programa com outras organizações como suporte para o alcance dos objetivos do programa (SILVA NETO et al, 2006). Neste sentido, foram avaliadas a existência de parcerias de apoio logístico, de assistência técnica e de capacitações sobre manipulação de alimentos.

De acordo com as falas dos entrevistados não existe nenhuma cooperação da prefeitura municipal local para apoio logístico. No entanto, os gestores reconhecem que essa é uma responsabilidade da própria Associação. Em relação a existência de parcerias de assistência técnica, se percebe um distanciamento de órgãos como a EMATER que deveriam atuar de forma mais intensiva nesse sentido, fazendo com que os produtores exerçam suas atividades produtivas sem nenhuma orientação técnica. 
E quanto as parcerias para capacitações sobre manipulação de alimentos foi identificada a presença de órgãos como SEBRAE, SENAI e EMBRAPA. Percebeu-se ainda que essa parceria foi motivada principalmente por questões de fiscalização e exigências burocráticas do programa.

\subsubsection{Controle social do programa}

O controle social no âmbito do PAA/Compra com Doação Simultânea tem, entre outras funções, acompanhar as operações de aquisição e distribuição dos alimentos (BRASIL, 2014). Foi identificado no município de Martins-RN que o Conselho Municipal de Assistência Social é o órgão responsável pelo controle social do programa. O diretor geral da Associação foi questionado também sobre a forma de realização do controle social, conforme a fala a seguir:

Tem o Conselho Municipal de Assistência Social né. E a maioria dos conselheiros eles atuam nas escolas, nas instituições que recebem né. Aí eles tão ali já fiscalizando né. Eles fazem parte de um conselho, dão o aval e já tão acompanhando. Porque a maioria dos conselheiros trabalham nessas instituições. No caso pessoas do CRAS, pessoas das escolas... então eles acompanham né. (Diretor Geral).

Conforme o diretor, o Conselho Municipal de Assistência Social é composto por representantes de todas as unidades recebedoras do programa, como hospitais, escolas estaduais e municipais e os CRAS, e esses conselheiros que fazem o acompanhamento e fiscalização das operações do programa.

\subsection{Eficácia}

Neste tópico, são apresentadas as evidências relativas à perspectiva da eficácia do PAA, expondo os resultados obtidos por meio da pesquisa documental nos dados da CONAB para verificar as metas físicas do programa e a percepção dos beneficiários fornecedores quanto a qualidade dos serviços prestados pela Associação responsável pela execução do programa e outros agentes que poderiam atuar junto aos agricultores.

\subsubsection{Metas do programa}

Verificar o desempenho do cumprimento das metas estabelecidas para o projeto após o seu término torna-se relevante, pois o não cumprimento das metas poderá ser um parâmetro para alocação de recursos em projetos futuros enviados pelas associações (BRASIL, 2014). Ou seja, caso a instituição executora não cumpra com o que foi formalizado, no ano seguinte poderá perder credibilidade e ter menos recursos destinados aos seus projetos. 
Foi tomado como critério de avaliação das metas do programa o último projeto executado pela AMARFRUTAS que teve início em junho de 2016 e término em janeiro de 2018, registrado com a Cédula de Produto Rural (CPR) de código RN/2016/02/0019 e foram analisadas as metas de alimentos comercializados e distribuídos e os recursos aplicados.

Tabela 2 - Meta de Alimentos Comercializados e Distribuídos

\begin{tabular}{lccc}
\hline Produto & $\begin{array}{c}\text { Quantidade } \\
\text { Executada (Kg) }\end{array}$ & $\begin{array}{c}\text { Quantidade } \\
\text { Formalizada (Kg) }\end{array}$ & $\begin{array}{c}\text { Percentual de } \\
\text { Execução da Meta (\%) }\end{array}$ \\
\hline Polpa de Acerola & $5.500,000$ & $5.500,000$ & $100 \%$ \\
\hline Polpa de Cajá & $3.500,000$ & $3.500,000$ & $100 \%$ \\
\hline Polpa de Cajarana & $12.000,000$ & $12.000,000$ & $100 \%$ \\
\hline Polpa de Caju & $11.000,000$ & $11.000,000$ & $100 \%$ \\
\hline Polpa de Goiaba & $12.000,000$ & $12.000,000$ & $100 \%$ \\
\hline Polpa de Manga & $11.999,968$ & $12.000,000$ & $99,99 \%$ \\
\hline Polpa de Maracujá & $1.500,000$ & $1.500,000$ & $100 \%$ \\
\hline Polpa de Tamarindo & $3.500,000$ & $3.500,000$ & $100 \%$ \\
\hline Total & & & $99,999 \%$ \\
\hline
\end{tabular}

Fonte: Site da CONAB

A tabela 2 evidencia que o último projeto executado pela AMARFRUTAS na cidade de Martins-RN conseguiu cumprir de maneira altamente eficaz a meta de alimentos comercializados e distribuídos para as unidades recebedoras, atingindo um percentual de 99,9999\% de execução do que tinha proposto no projeto inicial.

Tabela 3 - Meta de Recursos Aplicados

\begin{tabular}{lllc}
\hline $\begin{array}{l}\text { Recursos do } \\
\text { PAA }\end{array}$ & $\begin{array}{l}\text { Quantidade } \\
\text { Executada }\end{array}$ & $\begin{array}{l}\text { Quantidade } \\
\text { Formalizada }\end{array}$ & $\begin{array}{l}\text { Percentual de Execução } \\
\text { da Meta (\%) }\end{array}$ \\
\hline $\begin{array}{l}\text { Valor dos } \\
\text { Recursos }\end{array}$ & R\$ 441.149,90 & R\$ 441.150,00 & $99,99 \%$ \\
\hline Total & & & $\mathbf{9 9 , 9 9 \%}$ \\
\hline
\end{tabular}

Fonte: Site da CONAB

Ao se analisar a quantidade de recursos executados, conforme exposto na tabela 3, notase que, assim como a quantidade de produtos, o programa obteve um alto percentual de atingimento das metas estabelecidas, $99,99 \%$ do valor formalizado. Esses resultados demonstram que o planejamento executado pelos gestores do programa tem sido alcançado de forma eficaz e que a Associação não perderá recursos em projetos futuros, caso venha a ser classificada, em função do não atingimento das metas estabelecidas. 


\subsubsection{Qualidade dos serviços}

Além de estar relacionada ao alcance de metas (SILVA NETO et al (2006), Ghelman (2006) também relaciona a eficácia com a qualidade na prestação de serviços. Assim, com base em Brasil (2014) foram estabelecidos alguns aspectos relacionados à qualidade na prestação de serviços no programa que puderam ser avaliados pelos beneficiários fornecedores, sendo eles: divulgação e comunicação do programa, existência de assistência técnica, apoio logístico para entrega dos produtos e os pagamentos dos produtos.

Inicialmente, os beneficiários fornecedores foram perguntados por qual meio ficavam sabendo do início anual das atividades do Programa de Aquisição de Alimentos e das ações realizadas. Para esse questionamento, $100 \%$ dos respondentes informaram que a própria Associação faz o contato com eles e os comunicam sobre as atividades. Foi identificado que algumas vezes o contato é realizado por telefone ou alguém pertencente a direção da Associação vai até as residências dos beneficiários informar sobre a realização de reuniões e/ou repassar informações sobre o programa. Os comentários a seguir demonstram um grande esforço por parte do diretor geral da Associação no processo de comunicação com os sócios.

Sempre é César ${ }^{1}$ né, o diretor da Associação. (B.F. 3).

César sempre comunica a gente. Tudo ele orienta. A gente fica sabendo de tudo que acontece. (B.F. 15).

Em seguida, foi perguntado aos beneficiários fornecedores se eles recebiam algum tipo assistência técnica para apoiá-los no desenvolvimento das atividades produtivas de suas propriedades. Os resultados expostos na tabela 4, apontam que apenas $15 \%$ dos respondentes recebem ou já receberam algum tipo de assistência técnica, enquanto $85 \%$ afirmaram nunca ter recebido apoio de nenhum órgão nesse sentido. Entre os que responderam sim, um agricultor afirmou que recebe assistência da EMATER, enquanto outros dois disseram que a própria Associação orientava os agricultores.

Tabela 4 - Prestação de assistência técnica

\begin{tabular}{lcc}
\hline Assistência técnica & Frequência (n) & Percentual (\%) \\
\hline Sim & 3 & $15 \%$ \\
\hline Não & 17 & $85 \%$ \\
\hline Total & $\mathbf{2 0}$ & $\mathbf{1 0 0} \%$ \\
\hline
\end{tabular}

Fonte: Dados da pesquisa

\footnotetext{
${ }^{1}$ Sempre que os beneficiários fornecedores mencionarem César em seus comentários, trata-se do diretor geral da Associação AMARFRUTAS, César Alves Maia.
} 
Segundo Cunha (2015), os serviços de assistência técnica possuem um importante papel para a agricultura familiar, sendo essenciais para a eficácia da comercialização de alimentos em programas como o PAA e PNAE. No entanto, no caso analisado verifica-se que esses serviços são praticamente inexistentes, o que representa um ponto de melhoria a ser observado no contexto de execução do programa. Alguns dos comentários feitos pelos agricultores apontam para um distanciamento da EMATER e ainda ao fato do órgão priorizar mais ações burocráticas de algumas políticas públicas em detrimento da transferência de conhecimentos e tecnologias.

Antigamente nós tinha muito contato com a EMATER, mas hoje ela tá toda misturada com a prefeitura. (B.F. 1).

A EMATER só passa pra resolver negócio do seguro safra. Aí eles vem aqui. (B.F. 3).

Quando questionados sobre a forma de entrega dos produtos, $30 \%$ dos pesquisados afirmaram que entregam os produtos por meios próprios, $45 \%$ fazem a entrega com auxílio da Associação e $25 \%$ tanto fazem uso de meios próprios de entrega como recebem ajuda da Associação, conforme apresentado na tabela 5.

Tabela 5 - Forma de entrega das frutas

\begin{tabular}{lcc}
\hline Forma de entrega & Frequência (n) & Percentual (\%) \\
\hline Meios próprios & 6 & $30 \%$ \\
\hline Auxílio da Associação & 9 & $45 \%$ \\
\hline Ambas as formas & 5 & $\mathbf{2 5 \%}$ \\
\hline Total & $\mathbf{2 0}$ & $\mathbf{1 0 0} \%$ \\
\hline
\end{tabular}

Fonte: Dados da pesquisa

A partir dos comentários feitos pelos beneficiários fornecedores, foi possível perceber que a Associação presta uma boa assistência na logística de transporte das frutas comercializadas do PAA. Foi identificado que a instituição possui um carro e uma moto que fazem o serviço de recolhimento das frutas quando necessário e mesmo aqueles que fazem a entrega por meio próprios, reconhecem a disponibilidade da Associação caso precisem. Alguns comentários a seguir reforçam essa conclusão.

Eu mesmo levo, mas necessitando eles podem vir pegar. (B.F. 5).

A Associação vem buscar. Eles têm um carro disponível para pegar. Quando é pouca a gente vai deixar, mas sendo muita eles vêm buscar. (B.F. 10).

O último aspecto analisado em relação a qualidade dos serviços foi quanto a forma de pagamento e sobre a existência ou não de atrasos nos pagamentos dos produtos comercializadas no PAA/Compra com Doação Simultânea no município de Martins-RN. Com relação a forma de pagamento, foi identificado que ela é feita em dinheiro repassado pelo diretor da Associação. Os sócios, ao fazerem a entrega das frutas, tem seus produtos pesados e registrados pelo 
responsável pelo recebimento na instituição. Após isso, em data estabelecida pelo gestor da Associação, o pagamento é realizado. Seguem alguns comentários dos produtores.

A gente recebe em dinheiro vivo. Vai colocando as frutas lá e ele vai entregando as notinhas e depois presta conta. (B.F. 1).

Ele vai armazenando o produto que a gente leva aí quando tem uma quantidade razoável aí eles pagam de acordo com o preço que tem tabelado lá. (B.F. 3).

Quanto à existência de atrasos nos pagamentos dos produtos vendidos, os beneficiários fornecedores foram unânimes em afirmar que não há qualquer tipo de atraso. Acrescenta-se a isso, os comentários feitos a respeito da confiança existente por parte dos produtores na diretoria da Associação e na transparência de suas ações. Destacando-se as falas a seguir.

Lá é tudo honestamente, não tem sabotagem, não tem nada. Tudo que acontece eles passam na reunião. (B.F. 8).

Já faz um bocado de ano que eu sou sócio, mas até agora nunca teve enrolada não. Eles fazem tudo direito. (B.F. 15).

Os relatos acima demonstram a confiança dos beneficiários fornecedores com a Associação, fato que os motivam a manter uma relação recíproca de lealdade com a organização e fortalece os laços de interação entre ambos.

\subsection{Efetividade}

\subsubsection{Efeitos pretendidos sobre os beneficiários fornecedores}

Os resultados expostos a seguir analisam os efeitos pretendidos do PAA sobre o seu público-alvo, ou seja, os beneficiários fornecedores e consumidores. Esses resultados buscaram avaliar as seguintes finalidades do programa: inclusão socioeconômica, incentivo ao autoconsumo, fortalecimento da comercialização, promoção da diversidade e estímulo ao cooperativismo/associativismo, constantes nos incisos I, II, VII, VIII e IX do Decreto 7.775, respectivamente (BRASIL, 2012).

\subsubsection{Inclusão socioeconômica}

Em relação a inclusão socioeconômica dos beneficiários fornecedores do PAA/Doação Simultânea no município de Martins-RN, foi questionado incialmente se eles verificaram algum aumento da produção após o ingresso no programa. Conforme exposto no gráfico 1, 30\% afirmou ter havido um aumento da produção, $50 \%$ dos produtores acreditam que não houve nenhum tipo de modificação na quantidade de frutas produzidas em suas propriedades e os $20 \%$ restantes julgaram haver uma diminuição da produção. 
Gráfico 1 - Efeitos do PAA sobre a produção, renda e participação da família no trabalho

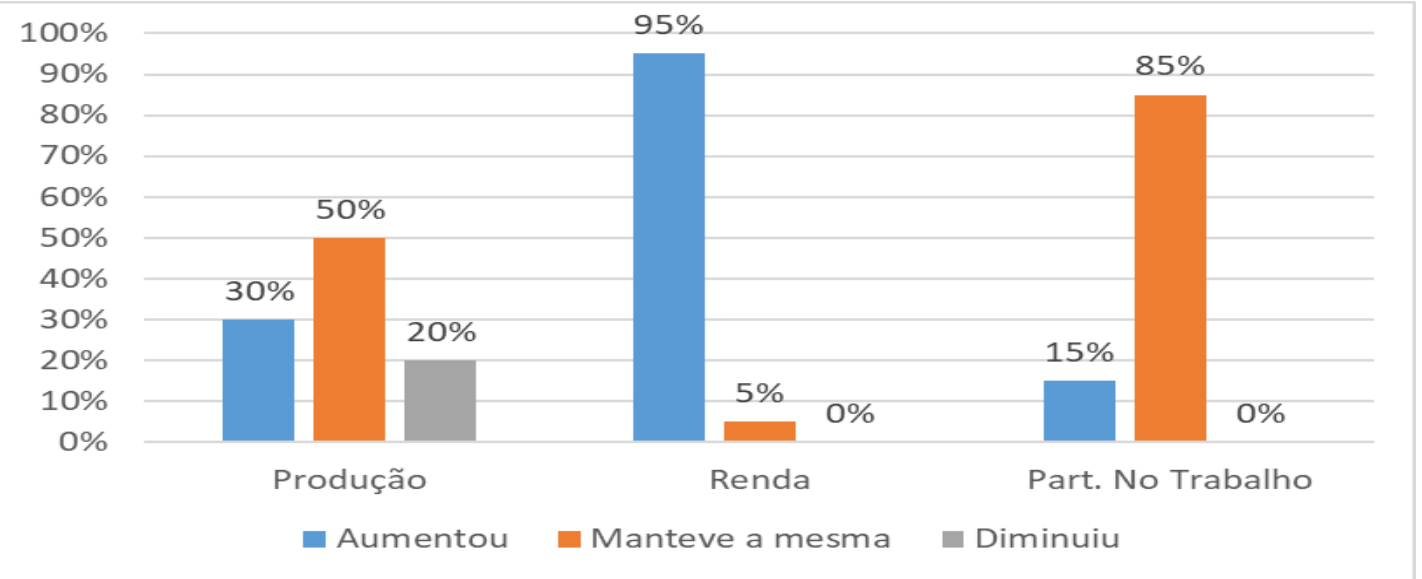

Fonte: Dados da pesquisa

Apesar de não ter tido um percentual predominante, dentre os que responderam que a produção aumentou, verifica-se como fatores motivadores desse aumento o desenvolvimento das ações da Associação na comunidade e a via certa para escoamento e comercialização dos produtos, conforme depoimentos a seguir.

\begin{abstract}
Sempre aumenta né. Porque quando não tinha essa instituição a gente perdia muitos produtos da gente que não tinha pra onde vender. Aí a gente consumia o que podia e o resto praticamente era perdido. Foi a coisa mais importante que foi instalado aqui em Martins foi essa Associação. (B.F. 3).
\end{abstract}

Na sequência, a pesquisa buscou saber como os beneficiários fornecedores percebem a influência do programa na renda de suas famílias. Conforme evidenciado no gráfico 1 , foi predominante a percepção do aumento da renda nos estabelecimentos investigados, com um total de 95\%. Apenas 5\% optaram pela opção "Manteve a mesma". Alguns comentários demonstram a percepção dos produtores quanto a esse aspecto. O comentário feito pelo B.F.7 aponta para a importância da atuação do programa no sentido de aproveitamento dos produtos que vendem e que antes eram desperdiçados, não tendo como obter qualquer tipo de renda a partir de sua comercialização.

Melhorou muito porque era um dinheiro que a gente não contava, era um dinheiro que se estruía. (B.F. 7).

Também foi identificado que $100 \%$ dos produtores pesquisados não obtêm suas receitas exclusivamente do PAA, sendo necessárias outras fontes de renda para o sustento das famílias com destaque para aposentadoria (55\%) e programas assistenciais (25\%). No entanto, alguns comentários foram feitos apontando o PAA como um importante complemento na renda dos agricultores. 
Quanto ao efeito sobre o trabalho das famílias na propriedade, verifica-se que $95 \%$ responderam que o programa não causou nenhum tipo de influência sobre o trabalho das famílias na propriedade, sendo que a mesma quantidade de pessoas das famílias que trabalhavam antes do programa permaneceu após o seu início. Além disso, segundo relato de um dos beneficiários fornecedores, verificou-se a existência do fenômeno do êxodo rural por parte dos jovens, sendo relatado pelo agricultor que todos os seus filhos já tinham migrado da zona rural para estudar e morar em cidades de maior porte do estado como Natal e Mossoró.

Em seguida, foi perguntado aos beneficiários fornecedores do programa, se houve alguma melhoria quanto algumas categorias relacionadas a qualidade de vida de suas famílias. O gráfico 2 a seguir demonstra os resultados alcançados nesse quesito.

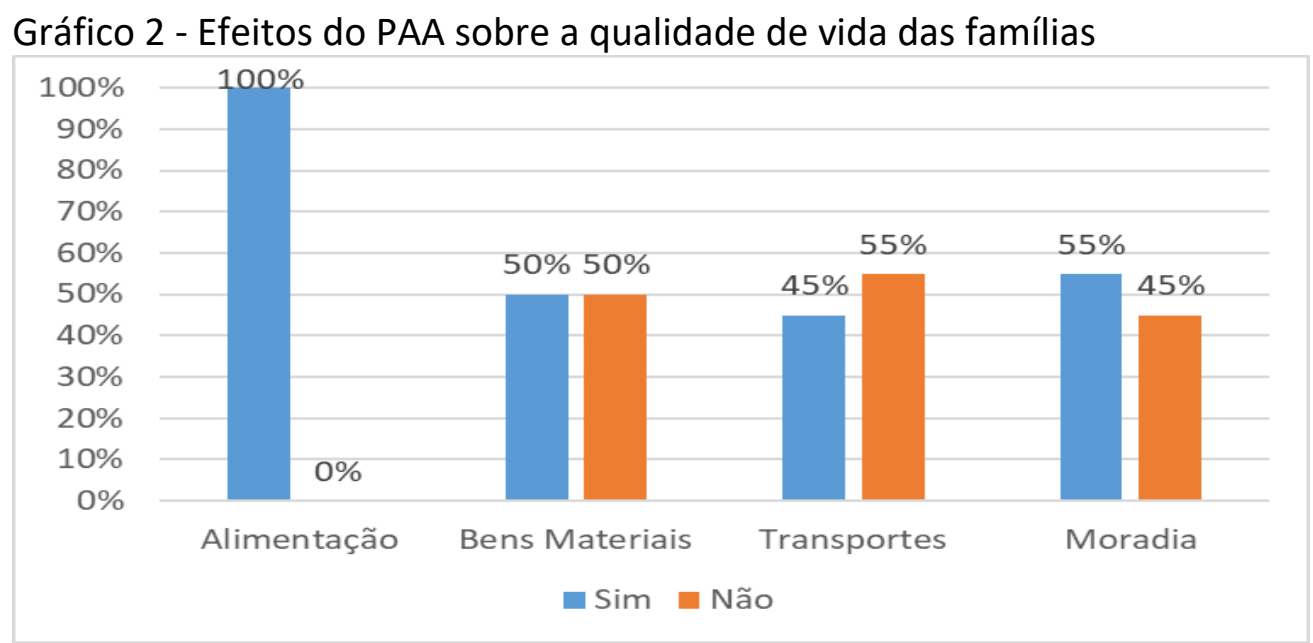

Fonte: Dados da pesquisa

Conforme o gráfico 2, verifica-se que a principal categoria influenciada pelo programa no questionamento foi a alimentação que obteve um percentual de $100 \%$ de respostas positivas por parte dos respondentes. Isso mostra que o atendimento à alimentação ainda deve ser tratado como uma das principais necessidades básicas a serem garantidas aos agricultores familiares e, com base nesses resultados, o PAA/Doação Simultânea tem contribuído neste sentido.

\subsubsection{Incentivo ao autoconsumo}

Segundo Gazolla e Schneider (2007) o autoconsumo pode ser entendido como a produção realizada no interior da unidade familiar e utilizada para suprimento de suas próprias necessidades. Assim, foi questionado aos agricultores se eles também se alimentavam dos produtos que eram comercializados no PAA. De acordo com os resultados da pesquisa, $100 \%$ dos agricultores afirmaram que também consomem domesticamente as frutas produzidas em suas propriedades. 
Não vendo tudo não. Também deixo o meu. Nós se alimenta aqui do suco da goiaba, da acerola, do caju. (B.F. 9).

A gente faz suco, come a goiaba em casa. Quando tem caju faz doce né. (B.F. 20).

Após a colheita dos seus produtos, os agricultores vendem uma parte da produção e a outra é consumida em casa. De acordo com os comentários a seguir, percebe-se que as frutas são utilizadas pelos produtores de três formas: para a produção de suco, consumo da fruta in natura e produção de doces que são utilizados como sobremesas nas refeições das famílias.

\subsubsection{Fortalecimento da comercialização}

No que se refere a comercialização dos produtos, foi questionado aos agricultores se eles tinham o PAA/Doação Simultânea como único meio de comercialização dos seus produtos. De acordo com dados da pesquisa, $95 \%$ dos produtores têm o programa como única via de comercialização. Apenas um produtor, que percentualmente representa $5 \%$ do total, disse que também vendia para outros mercados, conforme o comentário a seguir: "Vendo caju pra uma fábrica de polpa lá de Itaú ${ }^{2}$. Coloco um pouco alí na Associação e o resto levo pra lá. Agora é só o caju. A goiaba e a manga só levo pra aí mesmo." (B.F. 1).

Assim, com base nesse resultado, pode-se afirmar que o PAA/Doação Simultânea é a principal via de comercialização das frutas produzidas pelos agricultores, sendo que antes da existência do programa havia um grande desperdício da produção, pois não existia nenhuma forma de comercialização. Segundo relatos dos agricultores, uma parte das frutas eram utilizadas para consumo próprio e a outra parte era desperdiçada, de acordo com a fala do beneficiário fornecedor 8, exposta a seguir.

Antes de ter essa fábrica aí os nossos produtos era tudo desperdiçado né. Porque não tinha quem aproveitasse, se perdia muito. (B.F. 8).

Esse cenário, ao mesmo tempo que demonstra a importância do programa enquanto uma via certa de comercialização, aponta também as dificuldades dos produtores em atender outros mercados locais como supermercados e feiras, gerando uma grande dependência do programa, pois caso este seja encerrado em algum momento, os produtores voltarão a ter seus produtos desperdiçados por não existirem outras formas de comercialização. A figura 3 ilustra o cenário de comercialização dos produtores dos associados ao PAA/Doação Simultânea em Martins-RN.

\footnotetext{
${ }^{2}$ Município localizado na mesorregião Oeste Potiguar e distante $56 \mathrm{~km}$ do município de Martins-RN.
} 
Figura 3 - Cenário da comercialização dos produtos antes e depois do PAA

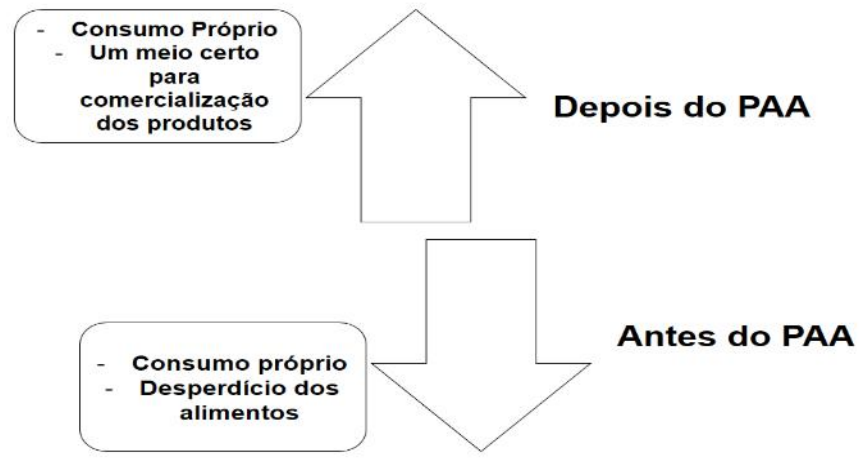

Fonte: Elaborado pelos autores

\subsubsection{Promover e valorizar a diversidade}

Outro aspecto analisado foi o incentivo do programa a promoção e valorização da diversidade. Segundo Wanderley (1999) todos os esforços de evolução das sociedades camponesas tradicionais são percebidos a partir do aperfeiçoamento da diversidade, por meio da introdução de novas culturas nos estabelecimentos produtivos. Assim, sendo essa uma das finalidades do programa, foi questionado aos produtores se eles passaram a produzir algum produto que não produziam antes de participarem do programa.

Conforme visto na tabela 6 a seguir, 45\% dos agricultores buscaram diversificar a sua produção em função do programa, enquanto os outros $55 \%$ afirmaram ter continuado com as mesmas culturas que já possuíam antes, fato que aponta para um empenho por parte dos produtores em diversificar a sua produção para comercializar os seus produtos no PAA/Doação Simultânea. Os principais produtos que os agricultores passaram a produzir em virtude do programa foram para maracujá e acerola, citados quatro vezes cada.

Tabela 6 - Diversificação da produção

\begin{tabular}{lcc}
\hline Diversificação da produção & Frequência (n) & Percentual (\%) \\
\hline Sim & 9 & $45 \%$ \\
\hline Não & 11 & $55 \%$ \\
\hline Total & $\mathbf{2 0}$ & $\mathbf{1 0 0 \%}$
\end{tabular}

Fonte: Dados da pesquisa

Ainda nesse sentido, chamaram atenção as falas de dois produtores que tentaram diversificar as suas produções, porém não obtiveram êxito. Nas falas são apresentados motivos distintos que dificultaram a produção. O primeiro motivo citado foi relativo as condições climáticas da região que nos últimos anos teve baixos índices pluviométricos, e o segundo fator apresentado foi a ocorrência de pragas. Em ambas as situações, caso houvesse um maior 
acompanhamento técnico junto aos produtores, os referidos problemas poderiam ser solucionados. Seguem os depoimentos.

Tentamos plantar maracujá e graviola, mas não deu certo por causa da seca. Aí ficou as mesmas coisas. (A.F. 11).

Tentei produzir maracujá na intenção de vender, mas deu doença e não vingou. (B.F. 15).

\subsubsection{Estimular o cooperativismo e o associativismo}

O último aspecto do programa avaliado segundo a percepção dos beneficiários fornecedores foi a influência do PAA no associativismo local. Os resultados inerentes a esse quesito são mostrados na tabela 7. Como pode ser visualizado, $75 \%$ do total dos produtores se associaram por influência do programa (Tabela 7). Segundo alguns comentários, o PAA surgiu como uma grande oportunidade para comercialização dos seus produtos e a possibilidade de complemento da renda da família. Já os $25 \%$ que julgaram não ter tido influência do programa na decisão de se associar, relataram que tomaram a decisão por convite do diretor da Associação que foi até suas residências e fez a proposta de participação.

Foi porque eu não tenho salário fixo e quando aparece uma coisa que pode melhorar pra você aí você aproveita a oportunidade. (B.F. 7).

O diretor da Associação viu que no meu sítio tinha de tudo aí deu a proposta. (B.F. 9).

Tabela 7 - Influência do PAA no associativismo

\begin{tabular}{lrc}
\hline PAA como motivador para se associar & Frequência $(\mathbf{n})$ & Percentual (\%) \\
\hline Sim & 15 & $75 \%$ \\
\hline Não & 5 & $25 \%$ \\
\hline Total & $\mathbf{2 0}$ & $\mathbf{1 0 0 \%}$ \\
\hline
\end{tabular}

Fonte: Dados da pesquisa

De acordo com dados documentais da associação, no ano de 2016 a organização contava com um total de 64 produtores associados, o que representa uma evolução de $73 \%$ em relação ao ano de 2010 que foi o ano em que a associação passou a executar os projetos do PAA/Compra com Doação Simultânea. Em seu início havia um total de 37 produtores associados.

\subsubsection{Efeitos Pretendidos sobre os Beneficiários Consumidores}

Esses resultados buscaram verificar a efetividade do programa quanto ao fornecimento de alimentação em quantidade, qualidade e regularidade necessárias aos beneficiários finais do programa, conforme estabelecido no inciso III do Decreto 7.775 (BRASIL, 2012). Assim, foi perguntado aos beneficiários consumidores sobre as percepções que eles tinham em relação a quantidade, a qualidade, a variedade e a regularidade de entrega dos alimentos no programa. Os resultados dessas questões estão demonstrados no gráfico 4, a seguir. 
Gráfico 4 - Percepção dos Beneficiários Consumidores sobre a Qualidade, Quantidade, Variedade e Regularidade de entrega das polpas recebidas

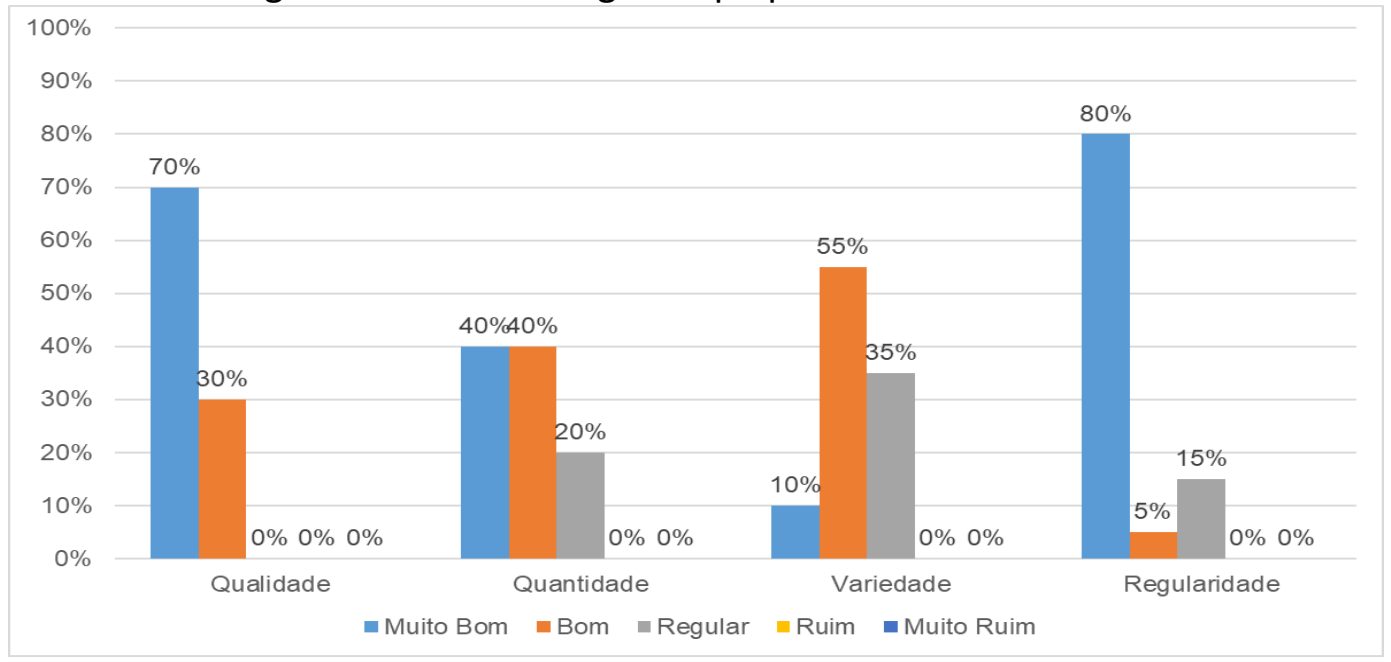

Fonte: Dados da pesquisa

Pelo gráfico 4, percebe-se que o item qualidade pode ser considerado como o mais bem avaliado entre os beneficiários consumidores, já que nenhum consumidor escolheu as opções "Regular", "Ruim" ou “Muito Ruim". Todas as avaliações ficaram entre "Muito Bom" com 70\% e "Bom" com 30\%. Esses números demonstram que a Associação está desenvolvendo um bom trabalho no processo de transformação das frutas em polpas, proporcionando um produto de alta qualidade para o consumidor final.

A quantidade dos produtos foi avaliada como muito "Muito Boa" por $40 \%$ dos beneficiários, sendo o mesmo percentual da opção "Boa". Já os 20\% restantes afirmaram que a qualidade dos produtos é regular. Segue alguns comentários feitos:

Poderia ser um pouco mais. (B.C. 11).

São muitas pessoas, então deve dividir com todos. (B.C. 15).

Por esses comentários, nota-se que ao mesmo que tempo em que há uma preocupação com o próximo por parte de alguns beneficiários, conforme demonstrado no comentário do B.C. 15, há também um desejo de recebimento de mais polpas como relatado nas outras falas. Ressalta-se ainda em relação a quantidade, que nas escolas e nos hospitais atendidos pelo programa os beneficiários consumidores já se alimentam dos produtos em sua forma final, ou seja, transformado em suco. Já no CRAS, local onde foi feita a pesquisa com os beneficiários consumidores, eles recebem quinzenalmente um total de 6 unidades de polpas de frutas de 100 gramas cada para utilizá-las como um complemento na alimentação da família.

A variedade das polpas recebidas pelos beneficiários consumidores foi o item com menor percentual de aprovação. E, por fim, quanto a regularidade, o gráfico 8 ainda mostra que a maioria 
do público pesquisado está satisfeita com os prazos de entregas das polpas, com 80\% julgando-a como "Muito Boa", 5\% afirmaram ser "Boa" e 15\% escolheram a opção "Regular".

\section{Considerações finais}

Este trabalho buscou avaliar a eficiência, eficácia e efetividade do Programa de Aquisição de Alimentos (PAA) na modalidade Compra com Doação Simultânea operacionalizado pela Associação Martinense dos Produtores de Frutas - AMARFRUTAS no município de Martins/RN a partir da adoção dos mapas estratégicos do Balanced Scorecard.

O estudo de caso analisado possibilitou verificar, pelo lado dos executores da política, os aspectos que impulsionam as instituições a atingirem os objetivos dos programas, constantes nas perspectivas do aprendizado e crescimento e da eficiência. E pelo lado dos beneficiários fornecedores e consumidores, foi possível avaliar as variáveis de alcance das metas físicas, a qualidade dos serviços prestados e o impacto sobre o público-alvo do programa, presentes nas perspectivas da eficácia e da efetividade.

A partir das análises feitas na perspectiva do aprendizado e crescimento, foi identificada a existência de treinamentos com os gestores locais do programa, principalmente com fins de atualização de questões burocráticas. Quanto ao capital da informação, foi constatado que os sistemas atendem as demandas do programa e que, em caso de necessidade, há um suporte da central da CONAB em Natal-RN para apoiar os executores locais do programa. Além disso, verificou-se uma grande satisfação por parte dos gestores locais em desenvolver atividades na Associação, trazendo com isso algum desenvolvimento na comunidade na qual fazem parte.

$\mathrm{Na}$ perspectiva da eficiência, verificou-se que os produtores atendem aos requisitos básicos de participação no programa. No que se refere ao estabelecimento de parcerias, foram identificadas lacunas quanto as parcerias para apoio logístico e prestação de assistência técnica aos produtores. Assim, essas questões surgem como pontos que podem ser corrigidos na atuação do programa.

Quando se trata das metas do programa, percebe-se um elevado percentual de eficácia, ficando próximo de alcançar os $100 \%$ tanto na totalidade dos alimentos comercializados quanto nos recursos aplicados, demonstrando que a instituição executora cumpriu o que foi formalizado em seu último projeto. E em relação a qualidade dos serviços do programa, assim como evidenciado na perspectiva da eficiência, a falta de assistência técnica foi mais uma vez tida como um fator negativo. No entanto, os demais itens relativos à qualidade dos serviços, como apoio 
logístico para entrega dos produtos, informações e divulgação do programa e pagamentos dos produtos comercializados, tiveram avaliação positiva por parte dos agricultores.

Com relação a efetividade do programa, pode-se destacar as seguintes evidências por parte dos beneficiários fornecedores: I) o programa exerce pouca influência sobre os níveis de produção das propriedades, sendo estes mais afetados pelos níveis de precipitação; II) o programa causou uma elevação da renda dos produtores, sendo esta percebida como um importante complemento para a renda das famílias; III) o programa não causou efeito sobre o trabalho da família na propriedade, havendo inclusive relatos de êxodo rural de jovens que moravam no campo; IV) o principal destino dos proventos obtidos com as vendas das frutas é a compra de alimentos, o que demonstra a importância do programa na alimentação das famílias dos agricultores; V) o programa passou a ser a principal via de comercialização dos produtos dos agricultores que, antes da existência do PAA/Compra com Doação Simultânea, desperdiçavam grande parte da produção; VI) praticamente metade dos produtores buscaram diversificar a produção em função do programa; e VII) houve um considerável aumento do número de sócios do programa desde o seu início.

O que demonstra o impacto proporcionado pelo programa no associativismo local. E por parte dos beneficiários consumidores, tem-se: I) altos percentuais de satisfação com a qualidade e regularidade da entrega dos produtos; e II) percentuais mais baixos de satisfação com a quantidade e as variedades das polpas fornecidas.

Assim, de modo geral, apesar da existência de algumas deficiências nas perspectivas relativas aos vetores de desempenho, principalmente no que se refere ao estabelecimento de parcerias, pode-se considerar que a maioria das medidas de resultado avaliadas no programa foram positivas, tendo-se como exceções os serviços de prestação de assistência técnica na perspectiva da eficácia, e os impactos sobre a produção e sobre o trabalho da família na propriedade, indicadores pertencentes a perspectiva da efetividade.

Por fim, sugere-se para estudos futuros a aplicação dos Mapas Estratégicos do Balanced Scorecard adaptado ao setor público para avaliar o Programa de Aquisição de Alimentos em outras localidades ou também outros programas públicos.

\section{Referências}

ANTICO, C.; JANNUZZI, P. de M. Indicadores e a gestão de políticas públicas. [2006?]. Disponível em:

<https://www.researchgate.net/profile/Paulo_Jannuzzi/publication/267697707_INDICADORES 
E_A_GESTAO_DE_POLITICAS_PUBLICAS/links/5718cecb08aed43f6322fa02/INDICADORES-E-AGESTAO-DE-POLITICAS-PUBLICAS.pdf> Acesso em: 20 Abr. 2017.

BRASIL. Decreto no 7.775, de 04 de julho de 2012. Regulamenta o art. 19 da Lei no 10.696, de 02 de julho de 2003, que institui o Programa de Aquisição de Alimentos, e o Capítulo III da Lei no 12.512, de 14 de outubro de 2011, e dá outras providências. Brasil, 2012. Disponível em: <http://www.planalto.gov.br/ccivil_03/_ato2011-2014/2012/Decreto/D7775.htm>. Acesso em: 20 Mai. 2017.

BRASIL. Lei no $\mathbf{1 0 . 6 9 6}$ de 02 de julho de 2003. Dispõe sobre a repactuação e o alongamento de dívidas oriundas de operações crédito rural, e dá outras providências. Disponível em: <http://www.camara.gov.br/sileg/integras/727660.pdf>. Acesso em: 20 Mai. 2017.

BRASIL. Lei no 11.326/2006 de 24 de junho de 2006. Estabelece as Diretrizes para a Formulação da Política Nacional da Agricultura Familiar e Empreendimentos Familiares Rurais. Disponível em: <http://www.planalto.gov.br/ccivil_03/_ato2004-2006/2006/lei/l11326.htm> Acesso em: 21 Mai. 2017.

BRASIL. Ministério do Desenvolvimento Social e Combate à Fome. Programa de Aquisição de Alimentos - Manual Operativo: modalidade compra por doação simultânea operação por meio de termo de adesão. 1a ed. Brasília: MDS, 2014. Disponível em:

<http://www.mds.gov.br/segurancaalimentar/aquisicao-e-comercializacao-da-agriculturafamiliar/entenda-o-paa/manualPAA_06.03.pdf>. Acesso em: 11 Ago. 2016.

BRESSER PEREIRA, L. C. Reforma do estado e administração pública gerencial. 4. ed. Rio de Janeiro: FGV, 2005.

COSTA, F. L. da; CASTANHAR, J. C. Avaliação de programas públicos: desafios conceituais e metodológicos. RAP Rio de Janeiro, v. 37, n. 5, p. 969-92, 2003.

GAZOLLA, M.; SCHNEIDER, S. A Produção da Autonomia: os "papéis" do autoconsumo na reprodução social dos agricultores familiares. Revista Estudos Sociedade e Agricultura, Rio de Janeiro, Ed. da UFRRJ, v. 15, p. 89-122, 2007.

GHELMAN, S. Adaptando o balanced scorecard aos preceitos da nova gestão pública. 2006. 86f. 2006. Dissertação (Mestrado em Sistema de Gestão pela Qualidade Total) — Universidade Federal Fluminense, Niterói.

JANNUZZI, P. M. Indicadores para diagnóstico, monitoramento e avaliação de programas sociais no Brasil. Revista do Serviço Público, Brasília, v. 56, n. 2, p. 137-160, abr./jun. 2005.

KAPLAN, R. S.; NORTON, D. P. A estratégia em ação: balanced scorecard. Rio de Janeiro: Elsevier, 1997.

KAPLAN, R. S.; NORTON, D. P. Mapas estratégicos - balanced scorecard: convertendo ativos intangíveis em resultados tangíveis. Rio de Janeiro: Elsevier, 2004.

KAPLAN, R. S.; NORTON, D. P. The balanced scorecard - measures that drive performance.

Harvard Business Review. Boston, v. 70, n. 1, p. 71-79, jan./fev., 1992.

KAPLAN, R. S.; NORTON, D. P. Using the Balanced Scorecard as a Strategic Management System. Harvard Business Review. Boston, v. 74, n. 1, p. 75-85, jan./fev., 1996.

LAMARCHE, H. A agricultura familiar: comparação internacional. Tradução: ângela Maria Naoko Tijiwa. Campinas, SP: Editora da UNICAMP, 1993.

MATTEI, L. O Papel e a Importância da Agricultura Familiar no Desenvolvimento Rural Brasileiro Contemporâneo. Rev. Econ. NE, Fortaleza, v. 45, suplemento especial, p. 83-91, out./dez., 2014. 
MELO, R. P. de. Gestão estratégica de programas: construção de um modelo baseado na integração do Balanced Scorecard ao processo de planejamento e orçamento público. In: Congresso CONSAD de Gestão Pública, 2013, Brasília. Anais do VI Congresso CONSAD de Gestão Pública. Brasília, 2013. Disponível em:

<http://banco.consad.org.br/bitstream/123456789/237/3/C3_TP_GEST\%C3\%830\%20ESTRAT\% C3\%89GICA\%20DE\%20PROGRAMAS\%20CONSTRU\%C3\%87\%C3\%830\%20DE\%20UM\%20MODEL O.pdf> Acesso em: 02 jun. 2017.

PEREIRA, M. E. B. de G.; LOURENZANI, A. E. B. S. Desafios e perspectivas do programa de aquisição de alimentos no município de Tupã-SP. Ciência e Natura, v. 36, n. 2, p. 230-240, 2014.

PORTO, S. I. Programa de Aquisição de Alimentos (PAA): política pública de fortalecimento da agricultura familiar e da agroecologia no Brasil. 2014. 131 f. Dissertação (Mestrado em Agroecologia) - Universidad Internacional de Andalucía, Baeza - Jaén, Espanha, 2014.

RICHARDSON, R. J. Pesquisa Social: métodos e técnicas. 3ae ed. 16ạ reimpr. São Paulo: Atlas, 2015.

SANO, H.; MONTENEGRO FILHO, M. J. F. As técnicas de avaliação da eficiência, eficácia e efetividade na gestão pública e sua relevância para o desenvolvimento social e das ações públicas. Desenvolvimento em Questão, v. 11, n. 22, p. 35-61, 2013.

SCHNEIDER, S.; CAZELLA, A.; MATTEI, L. Histórico, caracterização e dinâmica recente do PronafPrograma Nacional de Fortalecimento da Agricultura Familiar. In: SCHNEIDER, S.; SILVA, M. K.; MARQUES, P. E. M. (Orgs.) Políticas públicas e participação social no Brasil rural. Porto Alegre (RS): Editora da UFRGS, 2004. p. 21-49.

SILVA NETO, J. M., MELO, R. P.; PEREIRA, S. A. Resultados Notáveis na Administração Pública: Avaliação de Programas Utilizando Mapas Estratégicos e o Balanced Scorecard In: Encontro Nacional da Associação Nacional dos Programas de Pós-Graduação e Pesquisa em Administração, 2006, Salvador. Anais do XXX ENANPAD. Salvador: 2006. Disponível em: <http://www.anpad.org.br/enanpad/2006/dwn/enanpad2006-apsb-0701.pdf> Acesso em: 08 jun. 2017.

VERGARA, S. C. Projetos e Relatórios de Pesquisa em Administração. 15a ed. São Paulo: Atlas, 2014.

WANDERLEY, M. N. B. Raízes Históricas do Campesinato Brasileiro. In TEDESCO, J. C. (org.). Agricultura Familiar Realidades e Perspectivas. 2o ed. Passo Fundo: EDIUPF, 1999.

YIN, R. K. Estudo de Caso: planejamento e métodos. 5 a ed. Porto Alegre: Bookman, 2015. 